\title{
On the proportion of ballast versus non-ballast associated carbon export in the surface ocean
}

\author{
Frédéric A. C. Le Moigne, ${ }^{1}$ Richard J. Sanders, ${ }^{1}$ María Villa-Alfageme, ${ }^{2}$ Adrian P. Martin, ${ }^{1}$ \\ Katsiaryna Pabortsava, ${ }^{3}$ Hélène Planquette, ${ }^{1}$ Paul J. Morris, ${ }^{4}$ and Sandy J. Thomalla ${ }^{5,6}$ \\ Received 3 July 2012; accepted 5 July 2012; published 11 August 2012.
}

[1] The role of biominerals in driving carbon export from the surface ocean is unclear. We compiled surface particulate organic carbon (POC), and mineral ballast export fluxes from 55 different locations in the Atlantic and Southern Oceans. Substantial surface POC export accompanied by negligible mineral export was recorded implying that association with mineral phases is not a precondition for organic export to occur. The proportion of non-mineral associated sinking POC ranged from 0 to $80 \%$ and was highest in areas previously shown to be dominated by diatoms. This is consistent with previous estimates showing that transfer efficiency in such regions is low. However we propose that, rather than the low transfer efficiency arising from diatom blooms being inherently characterized by poorly packaged aggregates which are efficiently exported but which disintegrate readily in mid water, it is due to such environments having very high levels of unballasted organic $\mathrm{C}$ export. Citation: Le Moigne, F. A. C., R. J. Sanders, M. Villa-Alfageme, A. P. Martin, K. Pabortsava, H. Planquette, P. J. Morris, and S. J. Thomalla (2012), On the proportion of ballast versus non-ballast associated carbon export in the surface ocean, Geophys. Res. Lett., 39, L15610, doi:10.1029/2012GL052980.

\section{Introduction}

[2] The concept of the biological carbon pump emphasises the importance of oceanic primary production in the global

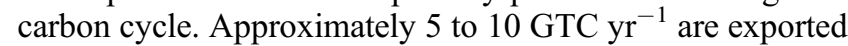
from the surface ocean into the ocean interior [Henson et al., 2011] mainly in the form of settling organic particles derived from phytoplankton production in the sunlit upper ocean. The coupling of oceanic production and export removes $\mathrm{CO}_{2}$ from the atmosphere and contributes to the buffering of the global climate system. Without the oceanic biological carbon pump, atmospheric $\mathrm{CO}_{2}$ levels would be almost twice as high as current concentrations [Sarmiento and Toggweiler,

\footnotetext{
${ }^{1}$ National Oceanography Centre, Southampton, Southampton, UK.

${ }^{2}$ Físíca Aplicada II, Universidad de Sevilla, Seville, Spain.

${ }^{3}$ Ocean and Earth Science, National Oceanography Centre, Southampton, University of Southampton, Southampton, UK.

${ }^{4}$ Department of Marine Chemistry and Geochemistry, Woods Hole Oceanographic Institution, Woods Hole, Massachusetts, USA.

${ }^{5}$ Ocean Systems and Climate Group, CSIR, Stellenbosch, South Africa.

${ }^{6}$ Department of Oceanography, University of Cape Town, Rondebosch, South Africa.

Corresponding author: F. A. C. Le Moigne, National Oceanography Centre, Southampton, European Way, Southampton SO14 3ZH, UK. (f.lemoigne@noc.soton.ac.uk)

C2012. American Geophysical Union. All Rights Reserved. 0094-8276/12/2012GL052980
}

1984]. The mode by which carbon is transferred downwards is therefore a key issue in the context of global climate change.

[3] In the deep ocean, strong correlations are observed between downward fluxes of biominerals (opal and calcite) and particulate organic carbon (POC). This observation inspired the "ballast hypothesis" which suggests sinking fluxes of minerals (such as biogenic calcite, biogenic opal, and lithogenic material such as clays) assist in driving the POC flux to the deep sea [Armstrong et al., 2001; François et al., 2002; Klaas and Archer, 2002]. Correlations between mineral and POC fluxes reflect both physical protection from remineralization and increasing aggregate density provided by denser minerals [François et al., 2002; Klaas and Archer, 2002].

[4] Whilst data from the deep ocean suggest that there is a correlation between mineral and POC flux, even if the details are opaque, in the upper ocean a paucity of data has hindered investigating whether such a relationship exists. This prevents an understanding of mechanisms that may promote particle export from the upper ocean [Honda and Watanabe, 2010; Sanders et al., 2010]. In addition, whilst the existence of non-ballast associated POC has been demonstrated in surface waters [Armstrong et al., 2001; Honda and Watanabe, 2010], little is known about its variability in the surface ocean.

[5] To explore this issue, we analysed ${ }^{234}$ Th derived estimates of POC and biomineral flux in the Atlantic and Southern Ocean [Morris et al., 2007; Thomalla et al., 2008; Sanders et al., 2010; F. Le Moigne et al., Insights from a POC and biominerals Th and Po derived export fluxes study at the Porcupine Abyssal Plain: Implications for the ballast hypothesis, submitted to Deep Sea Research, 2012]. We examine the variability of surface carrying coefficients, the contribution of the non ballast associated fraction of POC flux and the implications for the ballast hypothesis.

\section{Methods}

[6] We compiled 55 POC and biomineral (calcite and opal) export data derived from ${ }^{234} \mathrm{Th}$ measurements from 7 cruises (AMT-14, D285, D286, D321, D341, D350, D354, Table S1 in the auxiliary material [Thomalla et al., 2006; Morris et al., 2007; Thomalla et al., 2008; Sanders et al., 2010; Le Moigne et al., submitted manuscript, 2012]). ${ }^{1}$ During D285, D286, AMT-14, D321 and D341, total ${ }^{234} \mathrm{Th}$ was extracted and counted using methods described in Thomalla et al. [2006]. On D350 and D354 we used the

\footnotetext{
${ }^{1}$ Auxiliary materials are available in the HTML. doi:10.1029 2012GL052980
} 
Table 1. Carrying Coefficients (CCs) for Each Group Station Compared to Previous Studies ${ }^{\mathrm{a}}$

\begin{tabular}{|c|c|c|c|c|c|c|c|c|c|}
\hline Station Groups and Locations & $n$ & $a$ & $b$ & $c$ & $d$ (Intercept) & $r^{2}(p$ Value $)$ & $\begin{array}{l}\text { Sum of Squared } \\
\text { Residuals }\end{array}$ & $\mathrm{AICc}$ & $\begin{array}{l}\text { Proportion of } \\
\text { Nonmineral } \\
\text { Associated } \\
\text { Sinking } \\
\text { POC }^{\mathrm{d}}(\%)\end{array}$ \\
\hline Iceland (Ice) & 28 & $0.69(0.85)$ & $0.32(0.47)$ & $0.17(0.49)$ & $76.00(0)$ & $0.50(<0.001)$ & $154897(189432)$ & $251.1(253.9)$ & 32.6 \\
\hline $\operatorname{PAP}(P A)$ & 8 & $5.13(4.99)$ & $79.67(79.59)$ & $-0.29(-0.30)$ & $-2.77(0)$ & $0.81(0.020)$ & $2542(2548)$ & $67.4(58.1)$ & -2.6 \\
\hline Atlantic gyres $(A G)$ & 7 & $1.14(1.96)$ & $3.98(4.70)$ & $-0.01(-0.02)$ & $23.61(0)$ & $0.89(0.019)$ & $420(1394)$ & $56.7(51.1)$ & 37.5 \\
\hline Crozex (Cro) & 12 & $-0.11(0.02)$ & $0.16(0.27)$ & $0.45(2.04)$ & $105.45(0)$ & $0.20(0.20)$ & $18800(40920)$ & $101.0(106.6)$ & 73.9 \\
\hline All sites & 55 & $0.005(0.21)$ & $0.26(0.47)$ & $0.07(0.19)$ & $120.387(0)$ & $0.17(0.006)$ & $506919(825315)$ & $510.9(535.4)$ & 67.7 \\
\hline $\begin{array}{l}\text { W. Pacific Subartic gyre }{ }^{b} \\
\quad(150 \mathrm{~m})\end{array}$ & 21 & 0.05 & 0.35 & 0.17 & 0.41 & 0.58 & not estimated & not estimated & 81.6 \\
\hline Global surface $^{c}(0-115 \mathrm{~m})$ & 165 & 0.73 & 0.17 & not estimated & 3.35 & 0.33 & not estimated & \multirow{2}{*}{\multicolumn{2}{|c|}{$\begin{array}{l}\text { not estimated not estimable } \\
\text { not estimated not estimable }\end{array}$}} \\
\hline Global surface $^{c}(115-265 \mathrm{~m})$ & 165 & 0.41 & 0.06 & not estimated & 0.79 & 0.28 & & & \\
\hline
\end{tabular}

${ }^{234} \mathrm{Th}$ "small-volume" technique with ICP-MS assessment of recoveries for ${ }^{234} \mathrm{Th}$ extraction [Pike et al., 2005] with recoveries $94.2 \pm 3.4 \%$ for $\mathrm{D} 350$ and $90.6 \pm 6.7 \%$ for D354.

[7] Vertical profiles of ${ }^{234} \mathrm{Th}$ activity were converted to estimates of downward ${ }^{234} \mathrm{Th}$ flux using a one dimensional steady-state model [Buesseler et al., 1992]. These fluxes were then converted to estimates of downward particle flux using the ${ }^{234} \mathrm{Th}$ :POC or ${ }^{234} \mathrm{Th}$ :biomineral ratio on large (>53 $\mu \mathrm{m})$ particles collected using an in situ Stand Alone Pumping System (SAPS) deployed for $1.5 \mathrm{hrs}$ at a single depth beneath the mixed layer (see Table S1). Approximately 1500-2000 L of seawater was filtered onto a $53 \mu \mathrm{m}$ Nitex screen. Particles were then rinsed off the screen using thorium free seawater, and the particle suspension evenly split into four subsamples using a Folsom splitter.

[8] Each split was then analyzed for one of the following: ${ }^{234} \mathrm{Th}$, POC, calcite and opal. POC, BSi and PIC samples were analyzed as in Sanders et al. [2010]. On D285 and D286, particles were rinsed off the $53 \mathrm{um}$ mesh and were digested using aqua-regia followed by $\mathrm{HF} / \mathrm{HNO}_{3}$ digestion solution. Calcium concentrations were determined using an ICP-MS quadrupole [Planquette et al., 2009]. Large particle aluminum concentrations were not measured during AMT14, D321, D341, D350, D354, therefore literature values were taken from Lambert et al. [1984] (AMT-14) and Kuss and Kremling [1999] (D321, D341, D350 and D354). Al (Aluminium) fluxes for D285 and D286 are presented in Planquette et al. [2009]. Export integration depths for each station are given in Table S1.

[9] Lithogenic fluxes were estimated as (100/8xAl) [Honda and Watanabe, 2010] assuming that most particulate $\mathrm{Al}$ is of lithogenic origin, although it can be present in diatom frustules [Gehlen et al., 2002]. The estimates of lithogenic flux may be biased by using literature data, particularly for the AMT-14 data which cover a large spatial area. We attempt to control for this by using the aluminium concentration reported by Lambert et al. [1984] from the latitude band our sampling station lay within.
[10] To examine correlations between mineral and POC fluxes, we adopt a multiple linear regression analysis (MLRA) approach similar to Klaas and Archer [2002] and Honda and Watanabe [2010]. Total POC flux (POC total $\left._{\text {flux }}\right)$ was divided into portions associated with or carried by $\mathrm{BSi}$ $\left(\mathrm{POC}_{\mathrm{BSi}}\right)$, calcite $\left(\mathrm{POC}_{\mathrm{pic}}\right)$, lithogenic material $\left(\mathrm{POC}_{\text {lith }}\right)$ and residual POC $\left(\mathrm{POC}_{\mathrm{res}}\right)$. MLRA was used to fit the data to:

$$
\begin{aligned}
\mathrm{POC}_{\text {total }} & =\mathrm{POC}_{\mathrm{PIC}}+\mathrm{POC}_{\mathrm{BSi}}+\mathrm{POC}_{\text {lith }}+\mathrm{POC}_{\text {residual }} \\
& =\mathrm{a} \cdot \mathrm{PIC}_{\text {flux }}+\mathrm{b} \cdot \mathrm{BSi}_{\text {flux }}+\mathrm{c} \cdot \mathrm{Lith}_{\text {flux }}+\mathrm{d}
\end{aligned}
$$

where $a, b$ and $c$ are defined as "carrying coefficients (CCs)" [Klaas and Archer, 2002] while $d$ is the portion of POC that is not associated with any mineral. In order to study the regional variability in fluxes and $\mathrm{CCs}$, stations have been grouped according to their location and/or sampling time, following the Longhurst [1998] province approach to avoid erroneously grouping together stations that are geographically close but oceanographically dissimilar (Table S2).

[11] Two regression models were used, with the results being summarised in Table 1. The first has the regression being forced through zero (i.e., $d$ being set to zero) and the second allowing for an unassociated POC pool. Unfortunately it is not possible to use the familiar $r^{2}$ metric to compare the power of regressions with and without a free POC pool to describe the data as the latter regression does not pass through the mean of the data. We therefore use the corrected Akaike information criteria (AICc) to compare the ability of the two regressions to describe the dataset.

[12] The AICc decreases as the residual sum of squares decreases, but increases as the number of parameters in the regression increases to penalise for potential over-fitting [Burnham and Anderson, 2002]. In all cases the full regression gives a smaller sum of residual squared differences than the regression with zero intercept. In the two cases where AICc is smaller for the regression with zero intercept it is solely because of the penalty imposed on the full regression for having one more parameter ( 7 for PA and 12 for $A G)$. 

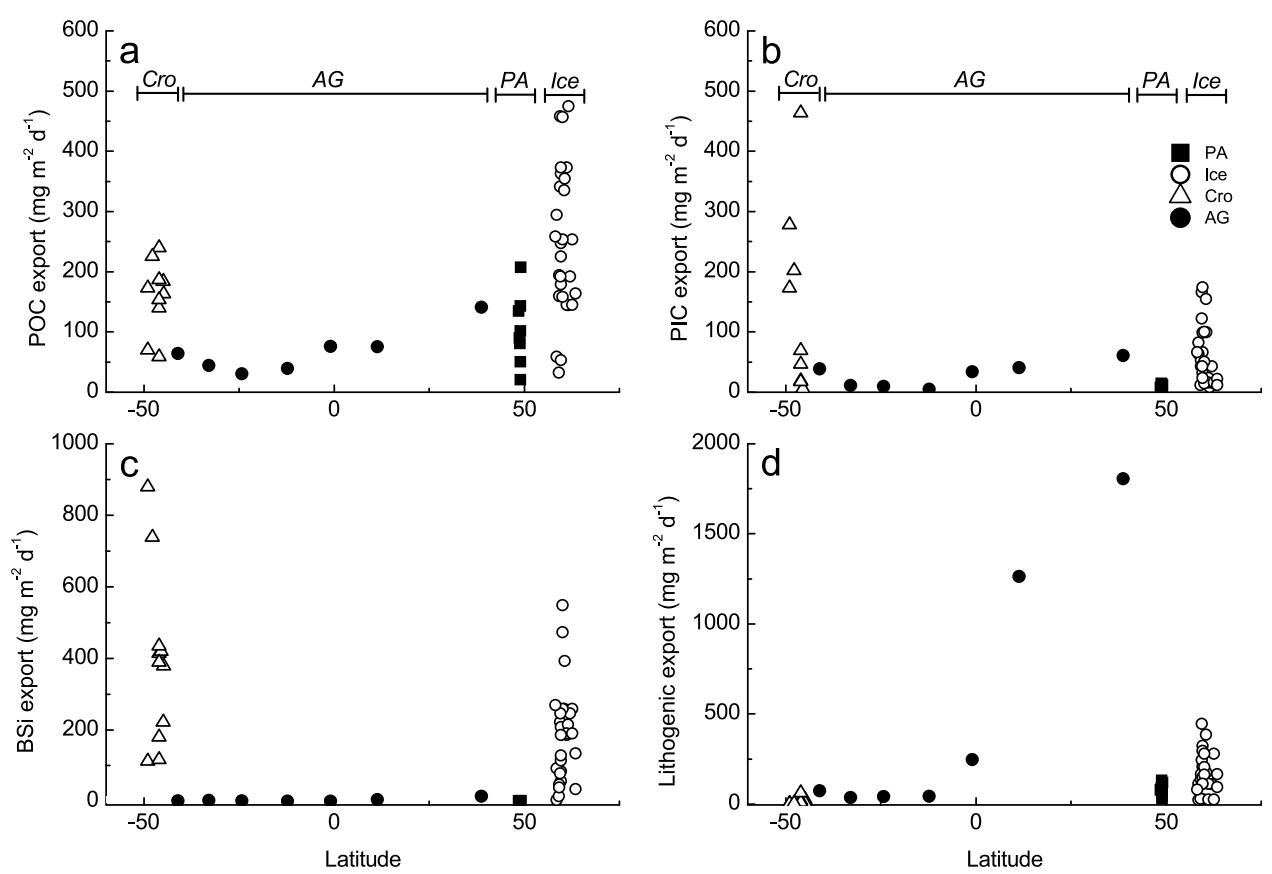

Figure 1. (a) POC, (b) PIC, (c) BSi and (d) lithogenic material export (in $\mathrm{mg} \mathrm{m}^{-2} \mathrm{~d}^{-1}$ ) as a function of latitude $\left({ }^{\circ}\right.$ ).

[13] Note that a larger carrying capacity only suggests a high mineral normalised POC flux, not a high absolute mineral associated POC flux, as the associated mineral flux may itself be small. Table S3 allows direct evaluation of this effect by using the calculated carrying coefficients to partition the observed POC flux into the three mineral associated pools and the non associated pool.

\section{Results and Discussion}

\subsection{General Considerations}

[14] Here we survey the magnitude of surface POC and biomineral export as a function of latitude. POC, PIC and BSi show high export in polar and sub-polar regions (Figure 1). At mid latitudes (between $45^{\circ} \mathrm{N}$ and $45^{\circ} \mathrm{S}$ ) POC and biomineral export are low. The latitudinal pattern of lithogenic material export seems to be correlated with the global pattern of aerosols deposition, the North Atlantic receiving most of the dust input relative to the South Atlantic and the Southern Ocean (respectively 43, 4 and 6\% total dust inputs to the global ocean [Jickells et al., 2005]). The presence of near-zero data points for PIC, BSi and lithogenic export, when POC export is occurring (Figure 1) suggests that the minerals are not an absolute precondition for organic carbon flux to occur. This suggests that a non-protected or ballasted POC pool plays a significant role in the surface ocean as previously demonstrated by Honda and Watanabe [2010] in the North Pacific. In the following section, we use information from the MLRA analysis to investigate the regional variability in the contribution of each ballast material to total POC flux and the relative proportions of ballast and non-ballast associated sinking POC.

\subsection{The Variability of Carrying Coefficients in the Surface Ocean}

[15] Table 1 summarises the carrying coefficients calculated for each mineral phase. In the Iceland (Ice) group the calcite $\mathrm{CC}$ is larger than the $\mathrm{CC}$ for either opal or lithogenic material, and the flux associated with calcite is almost as large as that associated with opal - Table S3. Previous observations show opal as an important ballasting biomineral in the region [Martin et al., 2011] during the spring bloom. This influence of calcite on the total flux can be explained by the fact that most of the Ice group stations were occupied in July-August 2007 and 2010 (21 of 28 stations, see Table S1), during which coccolithophores form an increasingly important component of the plankton [Poulton et al., 2010].

[16] The Porcupine Abyssal Plain (PA) and Atlantic gyres $(A G)$ groups display higher carrying coefficients for opal than for both calcite and lithogenic material. For PA the majority of the total POC flux comprises the fraction associated with opal but for AG, despite the relatively high carrying capacity, the opal associated flux is significantly smaller than that associated with calcite. Calcification rates are higher than silicification rates in both these locations [Poulton et al., 2006]. The calculated dominance of the opal associated flux for PA is due to the strong relationship between opal and POC, however the very high carrying coefficient implies that the direct opal ballasting effect may be negligible.

[17] The Crozex (Cro) station group also showed a higher value for $b$ than $a$ and more of the total POC flux was associated with BSi than with PIC (Table S3). Despite the lithogenic carrying capacity being larger than either of those for opal or calcite, low lithogenic fluxes meant that lithogenic associated POC remained a small fraction at Cro (Table S3). During the Crozex cruises (D285/286, see Table S1), plankton community structure shifted from a mixed Phaeocystis/diatom community to a microflagellate dominated community [Poulton et al., 2007]. Therefore, the absence of the calcifying group of phytoplankton may explain the negligible calcite $\mathrm{CC}$ of the Cro station group. The low $\mathrm{CC}$ for calcite and negative nature of both $\mathrm{CC}$ 
and fraction of POC flux are indicative of the signal associated with calcite being weak at this site.

[18] Honda and Watanabe [2010] concluded that $92 \%$ of sinking POC was associated with minerals (mainly opal) at $5000 \mathrm{~m}$ but that at the surface less than $20 \%$ of sinking POC was associated with minerals (either opal, calcite or lithogenic). We also find the majority of the total POC flux is not associated with minerals in the Southern Ocean (Table S3), but to a lesser extent.

[19] Whilst calcite and opal concentrations appear to be related to downward POC flux rates, they are not the sole determinands of POC export. It is likely that an important additional factor is the detail of the phytoplankton community structure (e.g., the production rates of silicifying vs. calcifying vs. non mineralizing groups) at the time of sampling. Future studies focussed on CCs should use indices of phytoplankton community structure (PCS) to address this issue.

\subsection{The Variability of Nonmineral Associated Sinking POC in the Surface Ocean}

[20] Our results indicate that the non mineral associated sinking POC flux in the surface ocean ranges from 0 (we consider the small negative proportion of non-mineral associated POC at $P A$ to be 0$)$ to $80 \%$ (Cro) of the total POC flux. The Ice and $A G$ station groups have similar fractions of non associated POC export (48 and 44\% respectively, Table 1). At Ice stations, diatom blooms are reported in spring [Martin et al., 2011] with coccolithophores in the post bloom period [Poulton et al., 2010].

[21] In the $A G$, PIC and BSi producers represented ranges of $3-24 \%$ and $4-27 \%$ of the surface ocean POC fixation respectively [Poulton et al., 2006]. This continual production of biominerals, and replenishment of concentrations that would be diminished by sinking, may lead to the relatively small fraction of POC export not associated with biominerals for both groups.

[22] The $P A$ group recorded the lowest fraction of unballasted export, effectively zero. Most of the $P A$ data are from cruise D341 where we were able to divide the flux into a fast sinking ballasted pool and a slow sinking pool which our initial observations suggested was unballasted [Riley et al., 2012; Le Moigne et al., submitted manuscript, Furthermore, the dataset presented here suggests that the fast pools contained rather little non biomineral associated POC during D341.

[23] The Cro station group displays the highest proportion of non associated POC, which is unexpected given the known role of diatoms in regulating Southern Ocean carbon export [Treguer and Pondaven, 2000]. This could be due to the presence of Phaeocystis [Poulton et al., 2007], a nonmineralizing organism documented as playing an important role in carbon export elsewhere in the ocean [DiTullio et al., 2000].

[24] Honda and Watanabe [2010] estimated the proportion of non associated POC as being approximately $82 \%$ of the total POC export in the Western Subarctic Pacific (at $150 \mathrm{~m}$ ), a value close to that found in the Cro group. In the Western Subarctic Pacific region the phytoplankton community is similar to the one around the Crozet plateau being composed mostly of pico and nanophytoplankton with a seasonal diatom peak in spring followed by picoeukaryotes and Synechococcus dominance in summer [Liu et al., 2004].
[25] This similarity in PCS between the two regions, coupled to the rarity of coccolithophores south of the Subantartic front in the Indian sector of the Southern ocean [Mohan et al., 2008] potentially explains the large proportion of non ballast-associated POC in both regions. Overall the occurrence of a non associated POC flux is not unique to the Western Subarctic Pacific as suggested by Honda and Watanabe [2010].

\subsection{Implication for the Ballast Hypothesis}

[26] In this remainder of this section, we explore how the occurrence of a large non-ballast associated POC flux in surface waters could potentially affect the strong correlations between POC and minerals found by Klaas and Archer [2002] at depth. Armstrong et al. [2001] found that the flux of organic matter at depths $>1800 \mathrm{~m}$ is directly correlated with the fluxes of ballast minerals at these depths. They hypothesized that this represented the remnants of a ballasted exported pool with a surface non mineral associated pool having been totally degraded in the upper ocean. Our direct observations of surface non associated flux support this concept, in providing evidence of a significant non mineral associated flux in the surface for several regions.

[27] Surprisingly, the pool of non-associated sinking POC seems to be more important in high latitude provinces where opal is often thought to play an important role in the transport of POC (e.g., the Southern Ocean or the Western Pacific Subarctic [Honda and Watanabe, 2010]). This discrepancy may result from the seasonal dynamics of export fluxes. These areas are dominated by intense diatoms bloom in spring. However, for the remainder of the year a non blooming regime dominates during which opal represents a low fraction of the total flux [Lam et al., 2011]. For instance, Cro (November-January) sampled a declining bloom that peaked in October [Venables et al., 2007]. Therefore, Cro stations generally represent the non blooming regime described in Lam et al. [2011].

[28] Armstrong et al. [2001] hypothesized that non-mineral associated POC disappears exponentially with depth based on sediment traps deployed along $140^{\circ} \mathrm{W}$ at the Equatorial Pacific site (EqPac). The EqPac region has unique biogeochemical features such as the upwelling of nutrient-rich water, and a divergence zone, which supports a highly productive phytoplankton community that contributes significantly to global new production [Chavez and Barber, 1987] and thus to export. Despite this unique setting, the concepts developed from the deep trap data appear relatively applicable across larger spatial scales with differing ecosystem structures.

[29] Klaas and Archer [2002] assumed that below $1000 \mathrm{~m}$ the non associated sinking POC was negligible. This assumption is very likely to be valid in areas where the proportion of non associated sinking POC is low. It is unclear however whether non associated sinking POC is completely absent at depth in settings where the non associated sinking POC in the surface is important (for instance in Honda and Watanabe [2010] and in the Cro station group in this study). Ignoring non associated sinking POC (e.g., forcing the intercept $d$ to 0 ) substantially affects the CCs. For instance, at Ice, when $\mathrm{d}$ is ignored, $\mathrm{CC}$ for lithogenic material becomes more important than the one for BSi. Similarly, the all sites CC (Table 1) for PIC becomes more important 
when $d$ is ignored. Hence, the CCs could be substantially distorted if the non mineral associated flux is significant.

[30] The most surprising result is that the highest levels of non associated POC export both in our study and that of Honda and Watanabe [2010] occur in regions viewed as being diatom dominated. This is consistent with the results of François et al. [2002], Lam et al. [2011], and Henson et al. [2012] who show that transfer efficiency (the efficiency with which material is transferred through the mesopelagic, not the efficiency with which it is exported from the photic zone to the mesopelagic) is low in high latitude diatom dominated areas. They argue that this is due to low levels of photic zone recycling and hence the export from the photic zone of poorly packaged aggregates which disintegrate readily in mid water in such regions. However we suggest that such regions have an unusually high proportion of non mineral associated POC export and an unusually small proportion of mineral associated export. This leads to an alternative hypothesis, namely that the low transfer efficiency in these regions is due to the large pool of non associated POC being entirely mineralized in the midwater region with the smaller pool of ballasted aggregates being efficiently transferred.

\section{Conclusions}

[31] A global compilation of surface POC and mineral export fluxes suggest that the proportion of POC associated with each mineral is driven by phytoplankton community structure more than latitude. In the surface ocean, the proportion of non associated sinking POC is highly variable and may be important at high latitude regions. Adjustments in community composition and the mineral content of the sinking particles will alter the efficiency by which POC is transported to depth. For example, predicted shifts of biomineralizing species such as diatoms toward smaller species [Bopp et al., 2005] may alter the partitioning of ballast vs. non-ballast associated sinking POC in the surface ocean and potentially increase the proportion of free POC. If this happens, community composition and the mineral content of the sinking particles will be affected and thereby alter the efficiency by which the POC is transported to depth. This is a critical issue for the ocean atmosphere partitioning of $\mathrm{CO}_{2}$ [Kwon et al., 2009].

[32] Acknowledgments. We would like to thank the captain and crew of the RRS Discovery and the D341-D350-D354 scientific teams. We also gratefully acknowledge Bob Head (PML), Darryl Green, Chris Marsay and Andy Milton (NOC) for assistance in analytical work. This work is part of the lead author's doctoral research and was supported by the CalMarO program, (E.U, grant agreement 215157) and by the U.K. Ocean 2025 program. The authors thank two anonymous reviewers for assisting in the evaluation of this paper.

[33] The Editor thanks two anonymous reviewers for assisting in the evaluation of this paper.

\section{References}

Armstrong, R. A., et al. (2001), A new, mechanistic model for organic carbon fluxes in the ocean based on the quantitative association of POC with ballast minerals, Deep Sea Res., Part II, 49(1-3), 219-236, doi:10.1016/ S0967-0645(01)00101-1.

Bopp, L., O. Aumont, P. Cadule, S. Alvain, and M. Gehlen (2005), Response of diatoms distribution to global warming and potential implications: A global model study, Geophys. Res. Lett., 32, L19606, doi:10.1029/2005GL023653.

Buesseler, K. O., et al. (1992), Carbon and nitrogen export during the JGOFS North Atlantic Bloom Experiment estimated from ${ }^{234} \mathrm{Th}:{ }^{238} \mathrm{U}$ disequilibria, Deep Sea Res., Part I, 39(7-8), 1115-1137, doi:10.1016/ 0198-0149(92)90060-7.

Burnham, K. P., and D. R. Anderson (2002), Model Selection and Multimodel Inference: A Practical Information-Theoretic Approach, 2nd ed. Springer, New York.

Chavez, F. P., and R. T. Barber (1987), An estimate of new production in the equatorial Pacific, Deep Sea Res., Part I, 34(7), 1229-1243, doi:10.1016/0198-0149(87)90073-2.

DiTullio, G. R., et al. (2000), Rapid and early export of Phaeocystis antarctica blooms in the Ross Sea, Antarctica, Nature, 404(6778), 595-598, doi:10.1038/35007061.

François, R., S. Honjo, R. Krishfield, and S. Manganini (2002), Factors controlling the flux of organic carbon to the bathypelagic zone of the ocean, Global Biogeochem. Cycles, 16(4), 1087, doi:10.1029/ $2001 \mathrm{~GB} 001722$.

Gehlen, M., et al. (2002), Unraveling the atomic structure of biogenic silica: evidence of the structural association of $\mathrm{Al}$ and $\mathrm{Si}$ in diatom frustules, Geochim. Cosmochim. Acta, 66(9), 1601-1609, doi:10.1016/S00167037(01)00877-8.

Henson, S. A., R. Sanders, E. Madsen, P. J. Morris, F. Le Moigne, and G. D. Quartly (2011), A reduced estimate of the strength of the ocean's biological carbon pump, Geophys. Res. Lett., 38, L04606, doi:10.1029/ 2011 GL046735.

Henson, S. A., R. Sanders, and E. Madsen (2012), Global patterns in efficiency of particulate organic carbon export and transfer to the deep ocean, Global Biogeochem. Cycles, 26, GB1028, doi:10.1029/ 2011 GB004099.

Honda, M. C., and S. Watanabe (2010), Importance of biogenic opal as ballast of particulate organic carbon (POC) transport and existence of mineral ballast-associated and residual POC in the Western Pacific Subarctic Gyre, Geophys. Res. Lett., 37, L02605, doi:10.1029/ 2009GL041521.

Jickells, T. D., et al. (2005), Global iron connections between desert dust, ocean biogeochemistry, and climate, Science, 308(5718), 67-71, doi:10.1126/science.1105959.

Klaas, C., and D. E. Archer (2002), Association of sinking organic matter with various types of mineral ballast in the deep sea: Implications for the rain ratio, Global Biogeochem. Cycles, 16(4), 1116, doi:10.1029/ 2001 GB001765.

Kuss, J., and K. Kremling (1999), Spatial variability of particle associated trace elements in near-surface waters of the North Atlantic $\left(30^{\circ} \mathrm{N} / 60^{\circ} \mathrm{W}\right.$ to $60^{\circ} \mathrm{N} / 2^{\circ} \mathrm{W}$ ), derived by large volume sampling, Mar. Chem., 68 , 71-86, doi:10.1016/S0304-4203(99)00066-3.

Kwon, E. Y., et al. (2009), The impact of remineralization depth on the air-sea carbon balance, Nat. Geosci., 2, 630-635.

Lam, P. J., S. C. Doney, and J. K. B. Bishop (2011), The dynamic ocean biological pump: Insights from a global compilation of particulate organic carbon, $\mathrm{CaCO}_{3}$, and opal concentration profiles from the mesopelagic, Global Biogeochem. Cycles, 25, GB3009, doi:10.1029/2010GB003868.

Lambert, C. E., et al. (1984), Particulate aluminium, iron and manganese chemistry at the deep Atlantic boundary layer, Earth Planet. Sci. Lett., 70, 237-248, doi:10.1016/0012-821X(84)90008-6.

Liu, H., et al. (2004), Community structure and dynamics of phytoplankton in the western subartic Pacific Ocean: A synthesis, J. Oceanogr., 60, 119-137, doi:10.1023/B:JOCE.0000038322.79644.36.

Longhurst, A. R. (1998), Ecological Geography of the Sea, 397 pp., Academic, San Diego, Calif.

Martin, P., et al. (2011), Export and mesopelagic particle flux during a North Atlantic spring diatom bloom, Deep Sea Res., Part I, 58(4), 338-349.

Mohan, R., et al. (2008), Ecology of coccolithophores in the Indian sector of the Southern Ocean, Mar. Micropaleontol., 67(1-2), 30-45, doi:10.1016/j.marmicro.2007.08.005.

Morris, P. J., et al. (2007), ${ }^{234}$ Th-derived particulate organic carbon export from an island-induced phytoplankton bloom in the Southern Ocean, Deep Sea Res., Part II, 54(18-20), 2208-2232, doi:10.1016/j.dsr2. 2007.06.002.

Pike, S. M., et al. (2005), Quantification of Th-234 recovery in small volume sea water samples by inductively coupled plasma-mass spectrometry, J. Radioanal. Nucl. Chem., 263(2), 355-360, doi:10.1007/ s10967-005-0062-9.

Planquette, H., et al. (2009), Origin of iron and aluminium in large particles ( $>53 \mathrm{um}$ ) in the Crozet region Southern Ocean, Mar. Chem., 115, 31-42, doi:10.1016/j.marchem.2009.06.002.

Poulton, A. J., R. Sanders, P. M. Holligan, M. C. Stinchcombe, T. R. Adey, L. Brown, and K. Chamberlain (2006), Phytoplankton mineralization in the tropical and subtropical Atlantic Ocean, Global Biogeochem. Cycles, 20, GB4002, doi:10.1029/2006GB002712.

Poulton, A. J., et al. (2007), Phytoplankton community composition around the Crozet Plateau, with emphasis on diatoms and Phaeocystis, Deep Sea Res., Part II, 54, 2085-2105, doi:10.1016/j.dsr2.2007.06.005. 
Poulton, A., et al. (2010), Coccolithophore dynamics in non-bloom conditions during late summer in the central Iceland Basin (July-Augus 2007), Limnol. Oceanogr., 55(4), 1601-1613, doi:10.4319/lo.2010.55. 4.1601 .

Riley, J. S., R. Sanders, C. Marsay, F. A. C. Le Moigne, E. P. Achterberg, and A. J. Poulton (2012), The relative contribution of fast and slow sinking particles to ocean carbon export, Global Biogeochem. Cycles, 26, GB1026, doi:10.1029/2011GB004085.

Sanders, R., P. J. Morris, A. J. Poulton, M. C. Stinchcombe, A. Charalampopoulou, M. I. Lucas, and S. J. Thomalla (2010), Does a ballast effect occur in the surface ocean? Geophys. Res. Lett., 37, L08602, doi:10.1029/2010GL042574.

Sarmiento, J. L., and J. R. Toggweiler (1984), A new model for the role of the oceans in determining atmospheric $\mathrm{pCO}_{2}$, Nature, 308(5960), 621-624, doi:10.1038/308621a0.
Thomalla, S., et al. (2006), Particulate organic carbon export from the North and South Atlantic gyres: The ${ }^{234} \mathrm{Th} /{ }^{238} \mathrm{U}$ disequilibrium approach, Deep Sea Res., Part II, 53(14-16), 1629-1648, doi:10.1016/j.dsr2. 2006.05.018.

Thomalla, S. J., A. J. Poulton, R. Sanders, R. Turnewitsch, P. M. Holligan, and M. I. Lucas (2008), Variable export fluxes and efficiencies for calcite, opal, and organic carbon in the Atlantic Ocean: A ballast effect in action?, Global Biogeochem. Cycles, 22, GB1010, doi:10.1029/ $2007 \mathrm{~GB} 002982$.

Treguer, P., and P. Pondaven (2000), Global change-Silica control of carbon dioxide, Nature, 406(6794), 358-359, doi:10.1038/35019236.

Venables, H., et al. (2007), Physical conditions controlling the development of a regular phytoplankton bloom north of the Crozet Plateau, Southern Ocean, Deep Sea Res., Part II, 54(18-20), 1949-1965, doi:10.1016/j. dsr2.2007.06.014. 